\title{
A Case of Hard Metal Lung Disease Resembling a Hypersensitive Pneumonia in Radiological Images
}

\author{
Keiko Okuno ${ }^{1}$, Kazuyuki Kobayashi ${ }^{2}$, Yoshikazu Kotani ${ }^{2}$, Hisashi Ohnishi ${ }^{3}$, \\ Chiho Ohbayashi ${ }^{4}$ and Yoshihiro Nishimura ${ }^{2}$
}

\begin{abstract}
A 42-year-old man was admitted to our hospital because of exertional dyspnea. He had worked as a metal grinder for 3 years, but has quited his job 1 month before admission. Chest radiography and high-resolution computed tomography showed diffuse ground-glass opacities like hypersensitivity pneumonitis shadows. The results of high-energy dispersion X-ray microanalysis indicated that the patient had hard metal pneumoconiosis associated with tungsten. Since the histological changes distributed terminal to respiratory bronchiole and surrounding alveoli, and macrophages engulfed black granules within the alveoli, in absence of giant cells, we considered this case to be a type of hypersensitivity pneumonitis of hard metal lung.
\end{abstract}

Key words: interstitial pneumonia, hard metal lung disease, tungsten, cobalt

(Inter Med 49: 1185-1189, 2010)

(DOI: 10.2169/internalmedicine.49.3049)

\section{Introduction}

Hard metal lung disease (HMLD) occurs in workers who are exposed to hard metal. Hard metal is a synthetic compound that contains tungsten carbide, cobalt, and other metals. As it is nearly as hard as diamond, it is useful for cutting and grinding metal tools, stones, and concrete. Several studies have reported the association between giant cell interstitial pneumonia (GIP) and exposure to hard metal, especially tungsten carbide. However, we encountered a case of HMLD with features resembling those seen in hypersensitivity pneumonitis (HP). Histological analysis showed macrophages that engulfed black granules within the alveoli, which is not a typical GIP pattern. To identify the granules, metal analysis was performed in the tissues by X-ray microanalysis.

\section{Case Report}

A 42-year-old man presented with a history of dry cough and dyspnea on effort for 6 months, after working for 3 years with chipped hard metal drills. He had a history of smoking 1.5 packs of cigarettes daily from the age of 14 to 35 years.

On physical examination, he was $170 \mathrm{~cm}$ tall and weighed $72 \mathrm{~kg}$. His temperature was $37.0^{\circ} \mathrm{C}$, pulse rate was $61 \mathrm{bpm}$, blood pressure was $100 / 59 \mathrm{mmHg}$, and respiratory rate was $15 / \mathrm{min}$. Respiratory sounds revealed bilateral late inspiratory fine crackles. Finger clubbing was not observed. There were no findings suggesting collagen diseases.

Pulmonary function tests showed restrictive impairment. The forced vital capacity (FVC) was $2.74 \mathrm{~L}$ (70.3\% of predicted) and the forced expiratory volume at $1 \mathrm{~s}$ (FEV1) was $2.44 \mathrm{~L}$ (86.8\% of predicted). Diffusion capacity (DLco) was reduced (65.9\% of predicted). Arterial blood gas analysis on room air showed a $\mathrm{pH}$ of 7.392, a $\mathrm{PcO}_{2}$ of $40.3 \mathrm{mmHg}$, and a $\mathrm{Po}_{2}$ of $93.8 \mathrm{mmHg}$.

A chest radiograph taken on admission showed bilateral fine reticular opacities (Fig. 1), though that taken 6 months ago had no findings. A thin-section computed tomography scan of the chest showed diffuse centriolobular micronodular opacities in the middle and lower lung fields (Fig. 2).

Bronchoalveolar lavage (BAL) fluid analysis yielded $8.4 \times$

\footnotetext{
${ }^{1}$ Department of Internal Medicine, Kasai Municipal Hospital, Kasai, ${ }^{2}$ Division of Respiratory Medicine, Department of Internal Medicine, Kobe University Graduate School of Medicine, Kobe, ${ }^{3}$ Department of Respiratory Medicine, Akashi Medical Center, Akashi and ${ }^{4}$ Department of Pathology, Hyogo Cancer Center, Akashi

Received for publication October 21, 2009; Accepted for publication March 10, 2010

Correspondence to Dr. Kazuyuki Kobayashi, kkoba@med.kobe-u.ac.jp
} 

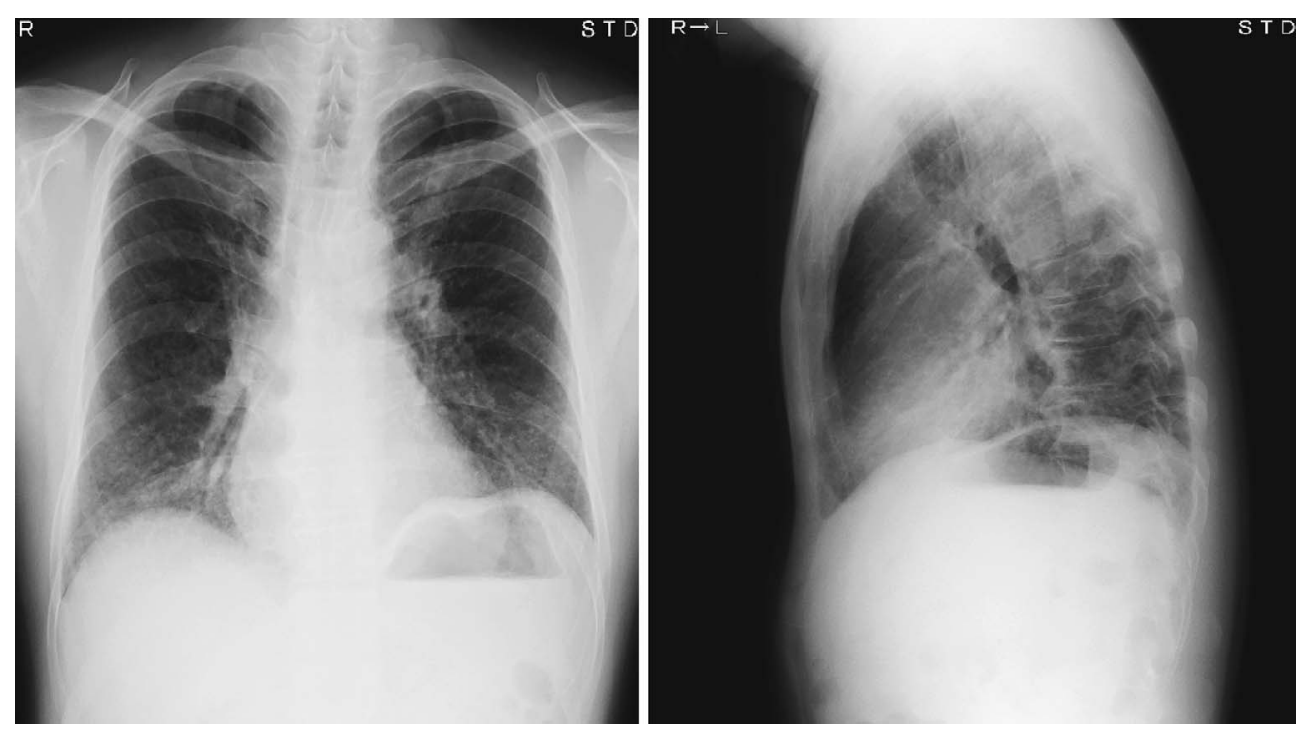

Figure 1. Chest radiograph on admission showing ground-glass opacities and volume loss in both lung fields.
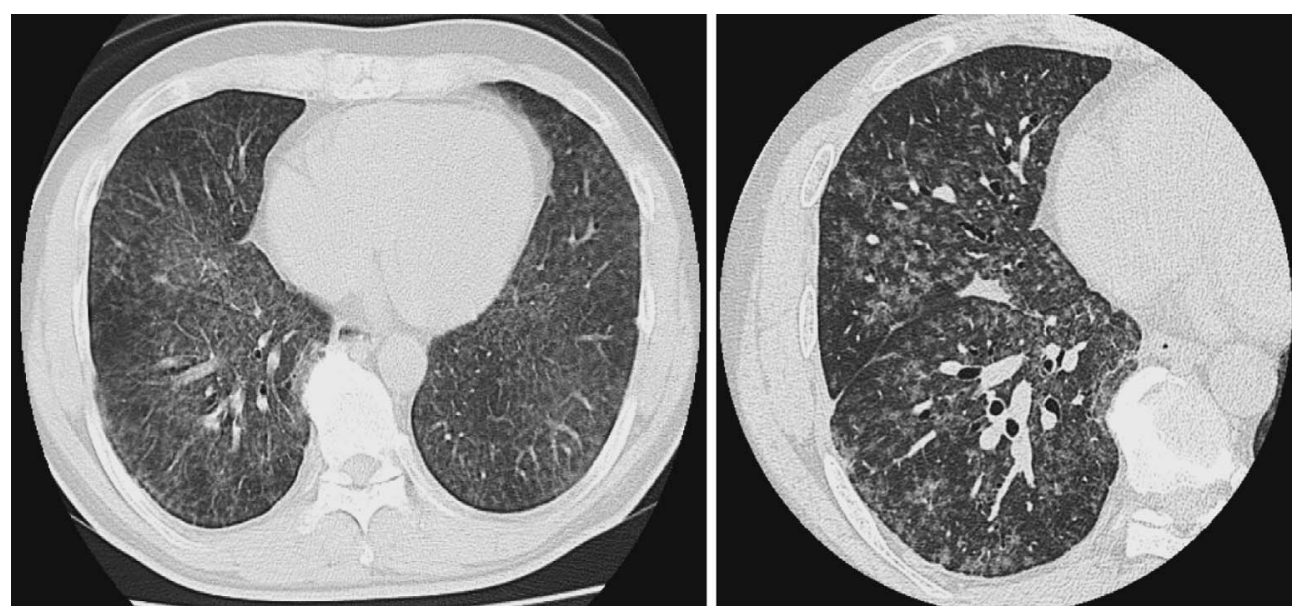

Figure 2. Chest computed tomography showing diffuse centrilobular micronodular opacities and a ground-glass shadow.

$10^{5}$ cells $/ \mathrm{mL}$ (49\% macrophages, $45 \%$ lymphocytes, $4 \%$ neutrophils, and $2 \%$ eosinophils). The CD4/CD8 lymphocyte ratio in the BAL sample was 0.62. Pathological specimens obtained by transbronchial lung biopsy revealed alveolitis with numerous macrophages. Alveolar structure was well preserved, however, small amount of collagen, lymphocytes, plasma cells and type 2 pneumocytes showed thickening of alveolar wall. Theses inflammatory findings were accentuated around a respiratory bronchiole. As intraalveolar mononuclear macrophages engulfed fine, black-colored granules (Fig. 3), the disease was assumed to be some kind of interstitial pneumonia related to hard metal. In order to make a definite diagnosis, a lung biopsy was performed with videoassisted thoracoscopy after 1 month.

The biopsy tissue was examined histologically and mineralogically (Fig. 4). Histological changes revealed obvious bronchial centric distribution and intervening area of distal parenchyma showed almost normal. Chronic inflammation with fibrosis continuously found from terminal to respiratory bronchiole and surrounding alveoli, in the absence of granuloma or polypoid intraalveolar granulation. Intraalveolar macrophages were decreased in comparison with transbronchial biopsy specimens. Tungsten was detected by highenergy dispersion X-ray microanalysis (EMAX-7,000 EDX HORIBA. 1td, Japan)(Fig. 5). After he quit his job, his respiratory symptoms almost completely disappeared and the findings of computed tomography scan of the chest improved without the need for corticosteroid administration (Fig. 6).

\section{Discussion}

Hard metal is a synthetic compound that contains tungsten carbide, cobalt, and other metals. Its hardness is $90 \%$ to $95 \%$ that of diamond, and it is used to make drill tips, tool edges, and armament components. During the manufacturing process, the raw materials are ball milled, and the resulting dry powder is mixed with wax, pressed into moulds, and 
a

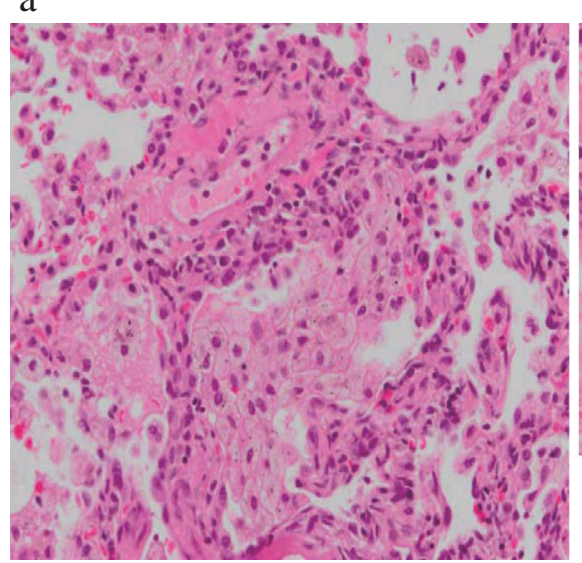

b

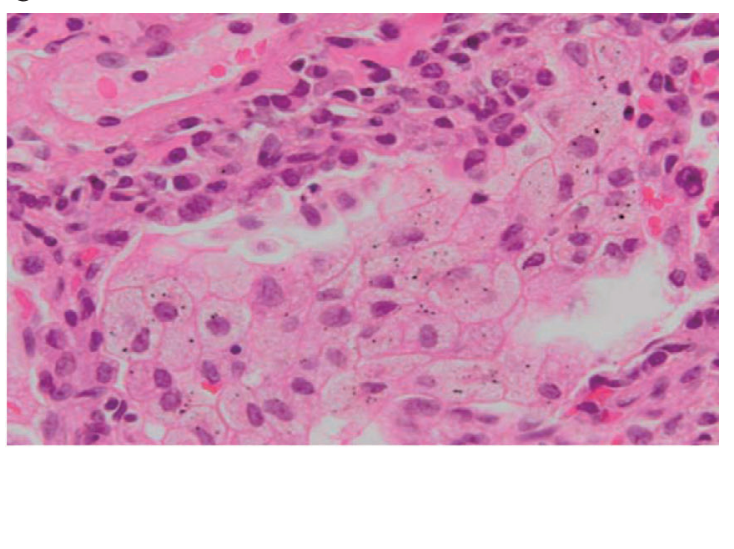

Figure 3. Histological findings of a TBLB specimen. a: Numerous bubbling macrophages in alveoli. b: A macrophage engulfing black particles.
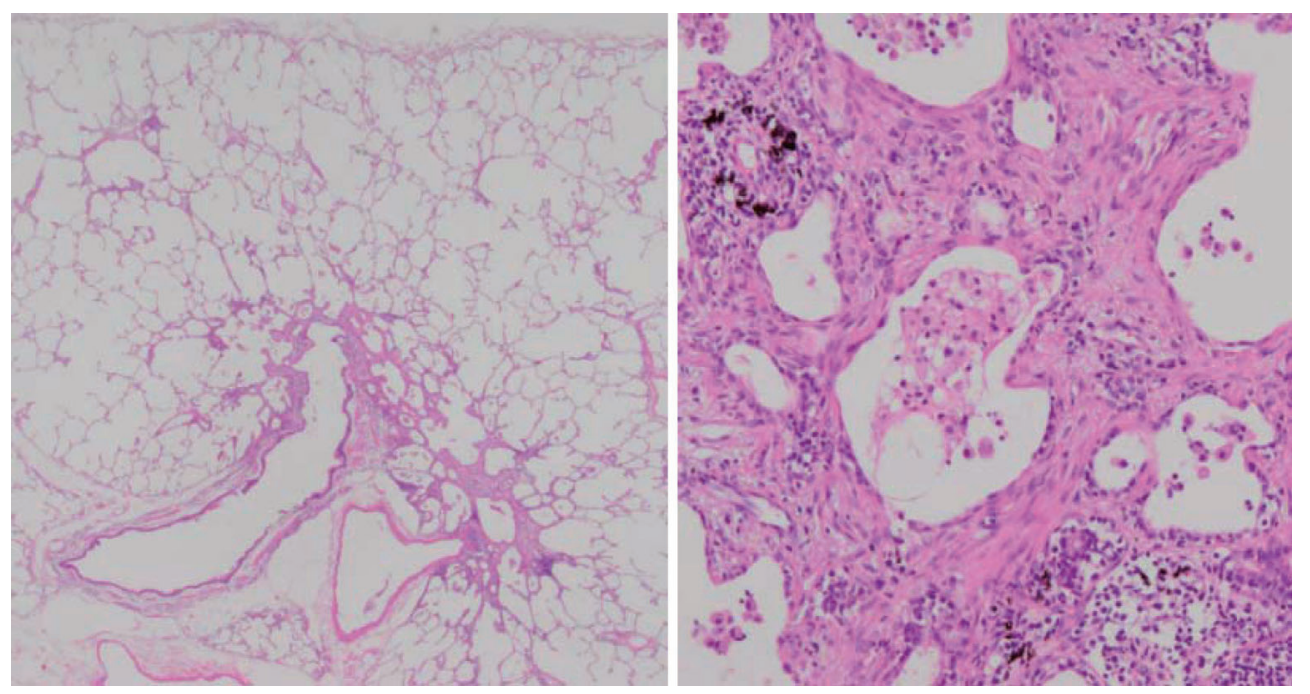

Figure 4. Surgical lung biopsy specimen obtained from the right S8 showing peribronchiolar scarring and accumulation of macrophages in adjacent spaces. The inflammation was improving in compare of TBLB specimen.

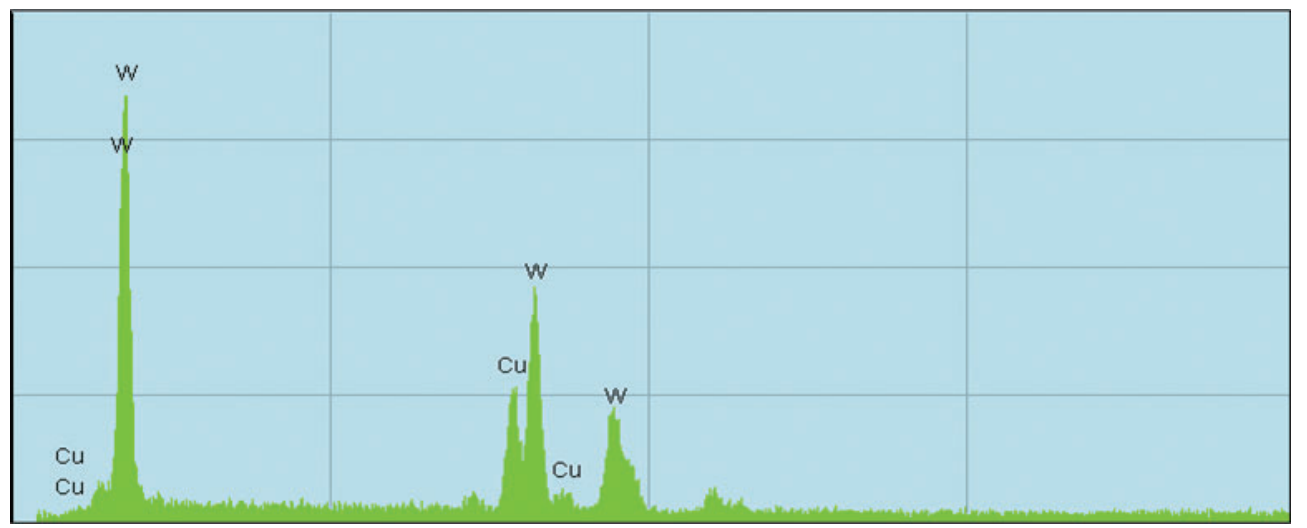

Figure 5. Tungsten was detected by energy dispersion X-ray microanalysis of a surgical lung biopsy specimen. Copper was detected by placing and examining the lung specimen on a copper wire gauze.

heated to temperatures between $1,400^{\circ} \mathrm{C}$ and $1,500^{\circ} \mathrm{C}$ (presintering). The presintered hard metal has the consistency of chalk and can be easily cut into the required shape. The shaped item is then heated to about $1,500^{\circ} \mathrm{C}$ (sintering) to 
a

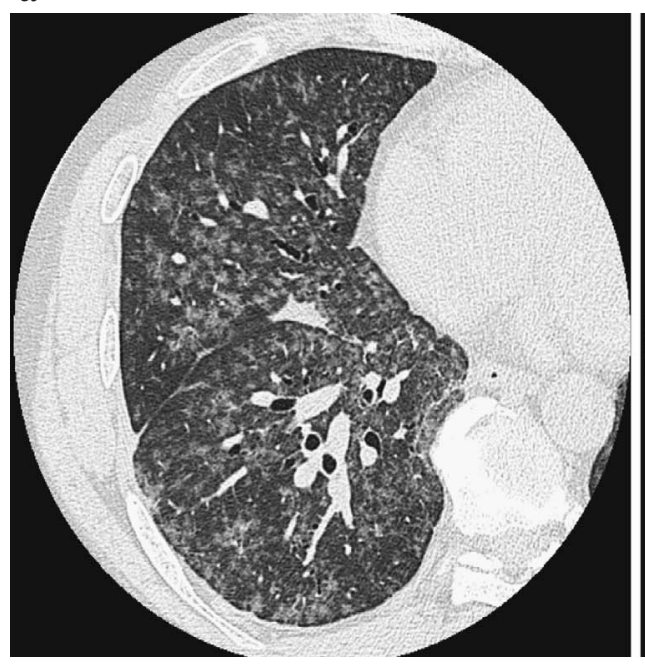

b

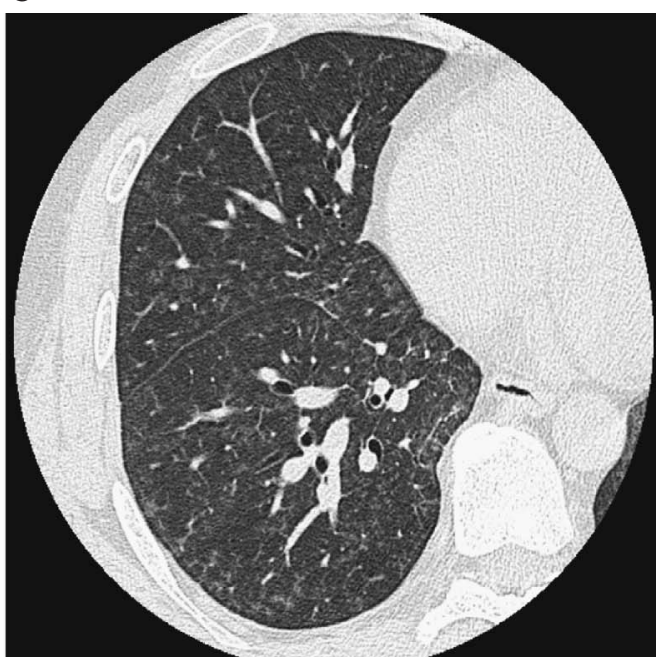

Figure 6. Chest computed tomography scans taken in June 2009 (a) and April 2009 (b) showing improvements in ground-glass opacities and volume loss.

produce hard metal. After sintering, the metal parts generally require additional finishing, which usually involves grinding, polishing, or additional machining. Because these final processes produce dust, the workers are exposed to hard metal via the respiratory tract.

Hard metal and methods for fabricating it were developed in several industrialized countries in the 1920s $(1,2)$. Until the 1980s, the histology of HMLD was mostly described as being nonspecific $(3,4)$. Recent studies suggest that the pathological findings of HMLD are predominantly those seen in interstitial pneumonia and fibrosis $(2,5)$. The diagnostic criteria were developed by Coates and Joseph $(3,6)$. The diagnosis of hard metal pneumoconiosis relies on (1) a history of exposure to hard metal dust, (2) pathognomonic symptoms (cough, dyspnea, and finger clubbing), (3) appearance of the lungs on X-rays, (4) histological examination of a lung biopsy and findings of 1 hard metal constituent in lung tissue. Our case corresponded with these points. Cobalt is highly soluble in biological fluids and after inhalation there is initial phase of rapid urinary excretion over about two days. Cobalt was not detected in lung tissue at this case but these specimens were taken at least two months after the patient had stopped work.

In 1968, Liebow and Smith classified chronic interstitial pneumonia into usual interstitial pneumonia, desquamative interstitial pneumonia, bronchiolitis obliterans interstitial pneumonia, and GIP (7). The histopathological findings of GIP include prominent intra-alveolar macrophages and giant cells showing cellular cannibalism (8), along with thickening of the interstitium and alveolar walls by mononuclear cells (9). In our case, multinucleated giant cells were absent, while peribronchiolar fibrosis and accumulation of macrophages were present. The main findings from examination of the surgical lung biopsy specimen were HP-like distribution. In the literature, only 7 cases of HMLD showing HPlike distribution have been reported (Table 1) $(1,10,11)$.
HP is caused by inhaled allergens that elicit lymphocytic inflammation in the peripheral airways and surrounding interstitium. We found centrilobular fibrosing lesions in the specimen, suggesting that inhaled hard metal was trapped at the bronchioles and triggered the inflammation of HMLD. It is controversial that allergic reaction participate this pathogenesis process or not, since there was no granulomas or polypoid granulation.

While tungsten carbide alone is not believed to play a role in the pathogenesis of HMLD, the combination of cobalt and tungsten carbide may be worse than cobalt alone. There have been 3 case reports regarding the pathogenesis of HMLD. The first stated that macrophages may phagocytose inhaled tungsten via CD163, and along with cytotoxic T lymphocytes, play an important role in forming an HMLD fibrotic lesion (12). The second stated that cobalt and tungsten carbide interacted with oxygen and resulted in the augmented production of toxic activated oxygen species (13). The last reported that HMLD was strongly associated with the amino acid residue Glu-69 of the HLA-DP beta chain (14).

Cugell described the cases of 3 hard metal workers who had the characteristic features of HP (1). After work-related exposure for 2 to 5 years, 2 of them developed cough, dyspnea, and flu-like symptoms. Bilateral crackles were noted on auscultation, and bilateral small nodular infiltrates were present on their chest radiographs. Patch test results using cobalt chloride were positive in all these workers.

We believe that HP is within the spectrum of changes seen in HMLD. However, the mean duration of exposure before the development of HMLD symptoms is 12.6 years. Thus, in our case, we think that an allergic reaction may also have been present.

HMLDs other than GIP that are found in hard metal industry workers are occupational asthma, other forms of chronic interstitial lung diseases, and HP. Hard metal lung 
Table 1. Clinical Profiles of Seven Hard Metal Lung Patients with Hypersensitivity Pneumonia Features

\begin{tabular}{|c|c|c|c|c|c|c|c|c|c|}
\hline Case & Age & $\begin{array}{l}\text { Se } \\
x\end{array}$ & $\begin{array}{l}\text { Tungsten } \\
\text { Present } \\
\text { (Y/N/NA) }\end{array}$ & Occupation & $\begin{array}{l}\text { Exposur } \\
\text { e } \\
\text { (y) }\end{array}$ & $\begin{array}{l}\text { Tissue } \\
\text { Sample } \\
\text { (date) }\end{array}$ & $\begin{array}{l}\text { Histolog } \\
\mathrm{y}\end{array}$ & $\begin{array}{l}\text { Last } \\
\text { Patient } \\
\text { status }\end{array}$ & $\begin{array}{l}\text { Cobalt/ } \\
\text { Tungsten } \\
\text { detected }\end{array}$ \\
\hline 1 & - & - & Y & $\begin{array}{l}\text { Dental } \\
\text { technician }\end{array}$ & NA & $\begin{array}{l}\text { B } \\
(1985)\end{array}$ & GIP,HSP & NA & N/- \\
\hline 2 & 51 & $\mathrm{~F}$ & $Y$ & $\begin{array}{l}\text { Blade } \\
\text { sharpener }\end{array}$ & 10 & $\begin{array}{l}\text { B } \\
(1993)\end{array}$ & $\begin{array}{l}\text { HSP,GIP } \\
\text { DAD }\end{array}$ & $\begin{array}{l}\text { Impaire } \\
\text { d }\end{array}$ & $N / Y$ \\
\hline 3 & 35 & $\mathrm{~F}$ & Y & NA & NA & $\begin{array}{l}b \\
\text { (NA) }\end{array}$ & HSP & $\begin{array}{l}\text { Impaire } \\
\text { d }\end{array}$ & $N / Y$ \\
\hline 4 & 60 & $M$ & Y & $\begin{array}{l}\text { Tool } \\
\text { grinder }\end{array}$ & 1 & $\begin{array}{l}b \\
(1972)\end{array}$ & HSP & $\begin{array}{l}\text { Impaire } \\
\text { d }\end{array}$ & $-/-$ \\
\hline 5 & 52 & $F$ & Y & $\begin{array}{l}\text { Tool } \\
\text { grinder }\end{array}$ & 2 & $\begin{array}{l}b \\
(1968)\end{array}$ & HSP & $\begin{array}{l}\text { Recurre } \\
\mathrm{nt}\end{array}$ & $-/-$ \\
\hline 6 & 65 & M & Y & $\begin{array}{l}\text { Tool } \\
\text { grinder }\end{array}$ & 5 & $\begin{array}{l}b \\
(1969)\end{array}$ & HSP & $\begin{array}{l}\text { Impaire } \\
\text { d }\end{array}$ & $-/-$ \\
\hline 7 & 53 & $\mathrm{~F}$ & $Y$ & $\begin{array}{l}\text { Tool } \\
\text { grinder }\end{array}$ & 3 & $\begin{array}{l}b \\
(1970)\end{array}$ & HSP & $\begin{array}{l}\text { Impaire } \\
\text { d }\end{array}$ & $-/-$ \\
\hline
\end{tabular}

Note. $\mathrm{B}=$ open-lung biopsy; $\mathrm{b}=$ transbrochial biopsy; $\mathrm{DAD}=$ diffuse alveolar damage; GIP = giant cell interstitial peumonia; HSP = hypersensitivity peumonia; NA or "-" = not Known or not done

showing HP features have only been described for 7 cases until date. (Table 1) We encountered a case of HMLD showing HP-like features, and tungsten was detected by highenergy dispersion X-ray microanalysis. This patient im- proved without the need for corticosteroid administration after diagnosis. Physicians should therefore pay attention to patients with respiratory symptoms who are workers exposed to hard metal.

\section{References}

1. Cugell DW. The hard metal diseases. Clin Chest Med 13: 269279, 1992.

2. Davison AG, Haslam PL, Corrin B, et al. Interstitial lung disease and asthma in hard-metal workers: bronchoalveolar lavage, ultrastructural, and analytical findings and results of bronchial provocation tests. Thorax 38: 119-128, 1983.

3. Coates EO, Watson JHL. Diffuse interstitial lung disease in tungsten carbide workers. Ann Intern Med 75: 709-716, 1971.

4. Nemery B, Verbeken EK, Demedts M. Giant cell interstitial pneumonia (hard metal lung disease, cobalt lung). Semin Respir Crit Care Med 22: 435-448, 2001.

5. Stefaniak AB, Virji MA, Day GA. Characterization of exposures among cemented tungsten carbide workers. Part I: J Expo Sci Environ Epidemiol 19: 475-491, 2009.

6. Joseph M. Hard metal pneumoconiosis. Australas Radiol 12: 92, 1968.

7. Liebow AA. New concepts and entities in pulmonary disease. In The Lung, Baltimore, 1968: 332-365.

8. Poletti V, Chilosi M, Olivieri D. Diagnostic invasive procedures in diffuse infiltrative lung diseases. Respiration 71: 107-119, 2004.
9. Choi JW, Lee KS, Chung MJ, et al. Giant cell interstitial pneumonia: high-resolution $\mathrm{CT}$ and pathologic findings in four adult patients. Am J Roentgenol 184: 268-272, 2005.

10. Naqvi AH, Hunt A, Burnett BR, et al. Pathologic spectrum and lung dust burden in giant cell interstitial pneumonia (hard metal disease/cobalt pneumonitis): review of 100 cases. Arch Environ Occup Health 63: 51-70, 2008.

11. Sakamoto O, Kosai S, Kohrogi H. A case of hard metal lung disease presenting a type of chronic hypersensitivity pneumonitis. Nihon Kokyuki Gakkai Zasshi 46: 535-541, 2008.

12. Moriyama H, Kobayashi M, Takada $T$, et al. Two-dimensional analysis of elements and mononuclear cells in hard metal lung disease. Am J Respir Crit Care Med 176: 70-77, 2007.

13. Kinoshita M, Sueyasu Y, Watanabe H, et al. Giant cell interstitial pneumonia in two hard metal workers: the role of bronchoalveolar lavage in diagnosis. Respirology 4: 263-266, 1999.

14. Potolicchio I, Mosconi G, Forni A, et al. Susceptibility to hard metal lung disease is strongly associated with the presence of glutamate 69 in HLA-DP beta chain. Eur J Immunol 27: 2741-2743, 1997.

(C) 2010 The Japanese Society of Internal Medicine

http://www.naika.or.jp/imindex.html 